\title{
Assessment of the Quality of Life in Patients with Epilepsy in the Populous Region of Baku
}

\author{
Asadova Ulker Asker \\ Department of Neurology of the Educational and Therapeutic Corps of the Azerbaijan Medical University, Baku, Azerbaijan \\ Email address: \\ asadli.u@mail.ru

\section{To cite this article:} \\ Asadova Ulker Asker. Assessment of the Quality of Life in Patients with Epilepsy in the Populous Region of Baku. Clinical Neurology and \\ Neuroscience. Vol. 5, No. 2, 2021, pp. 35-40. doi: 10.11648/j.cnn.20210502.17
}

Received: May 13, 2021; Accepted: May 28, 2021; Published: June 7, 2021

\begin{abstract}
An article establishes assessment of quality of life, severity of seizures and emotional condition 117 patients with epilepsy, over the age of $18(35.13 \pm 1.19)$ with different form epilepsy what started from 0 to 69 years $(14.22 \pm 1.26)$ in the Machtaga village. How showed analyzes of the survey results, the patients sub clinic $62(52.9 \%)$ and clinic $29(24.8 \%)$ pronounced measure depression and anxiety from scale Ziqmond and high measure severity of seizures from national hospital seizure severity scale (NHS3) (20-27 scores by 54 (46.1\%), (3-9 scores by 40 (34.2\%) patients, adversely affecting to their quality of life, assessment by questionnaire «QOLIE-10» (27.1 \pm 0.3$)$. Social status research revealed a high patients unemployment rate $(82(70.1 \%) \mathrm{p}=0.911)$. Between $70(59.8 \%)$ disability patients most had secondary group ( $\mathrm{p}=0.938)$. The number of lower secondary education and uneducated patient prevailed among native (28 (36.8\%)/7 (9.2\%)) and nonnative (11 $(26.8 \%) / 4(9.8 \%))$ village population $(\mathrm{p}=0.547)$. In population research $65(55.6 \%)$ patients were married, $52(44.4 \%)$ patients were alone $(\mathrm{p}=0.386)$. During the study it was revealed influence of ethnocultural characteristics patients to measure quality of life. A form of expression of religious beliefs, which, in the form of a clear implementation of the established religious rules, had a positive effect on the quality of life of patients from the hunhar and kechan mehelle, and mysticism in relation to religion, a form of upbringing in a family without encouraging intellectual development, and even prohibitions on obtaining an education, contributed to the formation passive personality with disabilities among patients from seidler mehelle, which affected their QOL negatively.
\end{abstract}

Keywords: Epilepsy, The Quality of Life, National Hospital Seizure Severity Scale, Ethnocultural Features

\section{Introduction}

Epilepsy is one of the most common diseases of the nervous system in children and adults. The incidence of this disease ranges from 1.5 to 18 , and in some developing countries it exceeds 30 cases per 1000 population [1-6]. The incidence rate of epilepsy is growing, according to the latest literature data (Beghi E, 2020) (61.4 / 100000), which ranges from $139.0 / 100000-48.9 / 100000$.

Today, the World Health Organization (WHO) regards it as one of the most important public health problems. Everyone can get epilepsy, regardless of age, gender, or race. Suffering from this ailment, it is not uncommon to face various kinds of discrimination. They are observed in getting an education, getting a job, getting married, as well as in the family and in the close environment. In addition to the social consequences, epilepsy has enormous economic costs. A few works are devoted to the study of the relationship between persons belonging to different races and ethnic groups, socioeconomic formations and epilepsy. This aspect of epilepsy remains largely unexplored. Perhaps scientific research in this direction will be able to point out the undoubted role of these factors in the structure of the incidence and prevalence of this dangerous disease.

More than 60,000 people suffer from this disease in Azerbaijan to. A series of works have been devoted to the study of epilepsy in the republic over the past 20 years. Studied its epidemiology and clinic as a whole, and in its various regions [7, 8]. As you know, the problems of people with epilepsy associated with the clinical manifestations of the disease limit their desire for self-realization and social activity, thereby reducing the indicators of their quality of life [4, 9-15].

As a result, in the framework of the studies mentioned 
above, the clinical and epidemiological indicators of epilepsy were studied in one of the large villages of the capital of the republic - Mashtaga, taking into account the influence of the ethnocultural characteristics of the indigenous and nonindigenous people living in this ancient settlement of Absheron on the assessment of their quality of life.

\section{Method}

The study of the quality of life of patients with epilepsy over the age of 18 years, living in the village of Mashtaga, in a comparative aspect of the ethnocultural characteristics of the population in the region was carried out during the period of clinical and epidemiological study of epilepsy among the population in the Mashtaga settlement of Baku city (20172019). The work was carried out in accordance with the protocol of the Ethics Committee No. 11 of the Azerbaijan Medical University (AMU) dated December 29, 2019 and the guidelines for conducting epidemiological studies prepared by the Commission on Epidemiology and Forecast of the International Antiepileptic League (1993) [16]. A cohort proand retrospective study of the epidemiology of epilepsy, taking into account the etiological and social aspects, was carried out on the basis of data on visits to the outpatient clinic in the village of Mashtaga, Sabunchu district, for the period from 2016 to 2019. Cases of active epilepsy were recorded based on the results of yard rounds, a continuous study of medical outpatient records of the combined children's and adult polyclinic department of the CCH No. 7, call records of the local ambulance station No. 14. The degree of depression (D) and anxiety (A) in patients with epilepsy was determined using the Ziqmond scale, the severity of seizures was determined by the NHS3 scale, according to which the total score was determined in the range from 1 to 27 . The QOLIE-10 questionnaire was used to assess the quality of life. in which each answer was graded on a scale of 1-5, with a higher score reflecting a lower quality of life, with a final score of 0-50. The age, sex of patients, their neurological symptoms, onset and causes of the disease were determined, the nature of drug therapy was studied at the beginning of the study and after optimization. When epilepsy was diagnosed for the first time, as well as to clarify the diagnosis, a clinical and neurological examination was carried out, including examination by a neurologist, electroencephalographic (EEG), magnetic resonance (MRI) and computed tomography (CT) studies.

The diagnosis and semiology of seizure types was determined according to the International Classification of Epilepsy and Epileptic Syndromes (ILAE) (New Delhi, 1989) and seizure types (Kyoto 1981).

To calculate the intensive indicators, we used data on the number and age and sex structure of the population served, provided by the outpatient department of the $\mathrm{CCH}$ No. 7 for the adult and child population of the Sabunchu district of Baku, as well as data from the 2019 census of the Republic of Azerbaijan.

The algorithms of the Statistics 6.0 program (Stat Soft Inc.,
USA) were used for statistical processing; for the assessment of qualitative parameters - Fisher's criterion. Correlation analysis was carried out using Pearson's rank correlation coefficient. The results are presented at the level of significant significance $\mathrm{p}<0.05$.

\section{Results and Discussion}

During the study period (2016-2019), 45000-46787 residents lived in the village (20371-24634 men and 2462522153 women). The indigenous population in 2017 was 37505 people, non-indigenous people who moved from different regions of Azerbaijan - 8295 people. Among them, there were 5261 people under 18 years old (2937 boys, 2324 girls), over 18 years old - 40539 people (20763 men, 19,776 women). The entire population is represented by Azerbaijanis.

Representatives of the indigenous population lived in the village compactly in three quarters (mehelle): Honhaar (descendants of the Hunnic Turkish), Kechan (descendants of the Massagets), Seidler (descendants of the Arabs), which for many centuries have passed from generation to generation, the established order of behavior, customs, faith, moral values, mythological ideas [17, 18]. Marriages between representatives of these quarters are not often observed to this day.

In the studied population of 197 patients with epilepsy (125 (63.5\%) from indigenous, 72 (36.5\%) from nonindigenous inhabitants), 117 persons were identified at the age from 18 to 75 years. The average age of the patients was $35.13 \pm 1.19$. The average age at the onset of various forms of epilepsy (from 0 to 60 years) was $14.22 \pm 1.26$. Among the identified patients, $76(65.0 \%)$ individuals were indigenous (33 (28.2\%) from Honhaar, 34 (29.1\%) from Kechan, and 9 (7.7\%) from Seidler mehelle), and $41(35.0 \%)$ patients were non-indigenous residents of the village. Idiopathic epilepsy was more detected in patients from Honhaar $(25(60.9 \%))$ and Seidler mehelle (6 (14.6\%)). Symptomatic prevailed in patients from Kechan mehelle (29 (38.1\%)) and nonindigenous people $(36(47.4 \%)),(p<0.05)$.

The severity of seizures on the NHS3 scale in patients from Kechan mehelle was assessed significantly higher (27 points) than in non-indigenous people (20 points). This may be due to the high frequency of occurrence among them of severe consequences of perinatal brain pathology (birth trauma, hydrocephalus, infantile cerebral palsy) and craniocerebral trauma, which, apparently, is associated with untimely visits to the antenatal clinic during pregnancy.

Among patients from Honhaar mehelle, persons with moderate severity of seizures were observed relatively more often (13 (39.4\%); 5 points) than from Kechan (10 (29.4\%); 9 points) and Seidler mehelle (3 (33.3\%); 9 points), but it was rated lower. Perhaps this is due to the desire to hide the disease, which is characteristic in the ethnic aspect for the indigenous population, as well as to the unauthorized cancellation of drug treatment, which was more often observed among patients from Seidler mehelle, and to the delayed treatment due to late detection of the disease. 
According to the literature, absences, as one of the forms of manifestation of idiopathic epilepsy, can often be unnoticed by the patient's relatives until they are complicated by generalized seizures $[5,19]$. Regarding cases of concealment of the disease, it can be noted that a similar phenomenon occurred in other countries of the world, for example, in most countries of Asia, parents hide the disease in their daughter, in order to preserve the opportunity to marry. In a study conducted in the southern Indian city of Kerala, 39\% of citizens surveyed called epilepsy a hindrance to marriage, and $55 \%$ of patients hid their diagnosis from their spouse. This was also the case in the populous province of the Republic of the Congo, in Lubumbashi, where epilepsy also posed a threat to women due to the likelihood of losing the chance to marry [20-22]. Severe seizures with a change in consciousness, accompanied by inappropriate behavior of patients, caused bewilderment on the part of others, which negatively affected the psych emotional status of patients. As is known from the literature, severe seizures play an important role in the maladjustment of patients, which significantly affects QoL [7, 9-11, 15, 23, 24]. As can be seen from diagram 2 , the psych emotional status, as determined by the Ziqmond scale, was assessed low in all patients $(8.91 \pm 0.17 ; \mathrm{m}=5, \mathrm{M}=13)$, and in non-indigenous patients, it was statistically significantly lower than in indigenous patients $(p=0.046)$. Among ethnic subpopulations, this indicator in patients from Kechan mehelle $(9.26 \pm 0.33)$ was lower than from Honhaar $(8.39 \pm 0.30)$ and Seidler mehelle $(8.78 \pm 0.66)$. In the study, the majority of patients were dominated by subclinical $(62(52.9 \%)$ cases $)$ and clinical forms of depression and anxiety (29 (24.8\%) cases). In patients with subclinical ( $8-10$ points) pronounced signs of anxiety and depression both from indigenous (46 (52.6\%)) (21 (51.5\%) from Honhaar, 19 (52.9\%) from Kechan, 6 (55\%) from Seidler mehelle) and 16 of non-indigenous residents $(53.7 \%)$, no significant difference was found in the percentage. Signs of anxiety and depression, expressed clinically (above 10 points) in non-indigenous patients $((29.3 \%) 16$ individuals), prevailed over indigenous patients ((22.4\%) 13 individuals), (4 (12.1\%) from Honhaar, 8 (32.4\%) from Kechan, 1 (11.1\%) from Seidler mehelle)).

There were fewer patients with no pronounced symptoms of depression and anxiety (0-7 points), 26 (22.2\%) cases. Among them, 9 (17.1\%) were non-indigenous and 17 (25\%) were indigenous (8 (36.4\%) Honhaar, 7 (14.7\%) Kechan, 2 $(22.2 \%)$ Seidler mehelle). In addition to the clinical manifestations of the disease (frequency and severity of seizures, the form of epilepsy) and psych emotional status, the quality of life of patients with epilepsy is also influenced by their social status $[4,9,10,12-15]$.

As follows from Table 1, with study of the social status of patients, the number of unemployed persons, both indigenous (53 (69.7\%)) and non-indigenous (29 (70.7\%)) was significantly higher than that of workers (laborers, drivers) (23 $(30.3 \%)$ of the indigenous, $12(29.3 \%)$ non-indigenous people). Perhaps, due to material motivation, working patients rated their QoL better than unemployed ones. Among $70(59.8 \%)$ persons with disabilities, the majority were patients with symptomatic epilepsy from Kechan mehelle 23 $(67.6 \%)$ and from non-indigenous residents 26 (63.4\%). The number of patients receiving disability from Honhaar and Seidler mehelle was comparatively smaller (14 (42.4\%)) (p $<0.05$ ), but due to late detection and complicated course of the disease, they all received the second group of disability. Persons with disabilities assessed QoL positively, which, apparently, is associated with a certain material support. The level of education in the studied 117 patients was as follows: patients with incomplete secondary education accounted for $33.3 \%$ (39 people), and 9.4\% (11 people) were generally uneducated. The reason for the low education was the severe course of the disease and the prohibitions by the parents from the indigenous inhabitants, more often from the Seidler mehelle, to attend school. Patients who received education rated QoL lower than those who were uneducated. A conscious attitude towards their disease, especially of patients from the Honhaar mehelle, where the number of educated people prevailed, led to self-stigmatization.

Patients, trying to avoid potential discrimination, independently limited social activity and ignored their own social needs, which subsequently negatively affected QoL. According to many authors, self-stigmatization in epilepsy negatively affects the QoL of patients [4, 12, 17]. A study of the marital status of patients revealed that the number of married persons $(65(55.6 \%))$ outnumbered single persons (52 (44.45\%)). Patients who started a family rated QoL higher than non-family patients. Feelings of compassion and support from family members increased confidence and decreased fear of seizures, which had a positive impact on QoL. In the work of Japanese researchers, carried out in 2015, it was shown that the support of relatives improves the mental health of an individual and his quality of life [25].

Table 1. Social Status of Epilepsy Patients.

\begin{tabular}{|c|c|c|c|c|c|c|}
\hline \multirow{2}{*}{ Social status of patients } & \multicolumn{3}{|c|}{ Indigenous people } & \multirow{2}{*}{$\begin{array}{l}\text { Indigenouspeopl } \\
\text { e. Total: № } 76\end{array}$} & \multirow{2}{*}{$\begin{array}{l}\text { Non-indigenous } \\
\text { people № } 41\end{array}$} & \multirow{2}{*}{$\begin{array}{l}\text { Altogether: } \mathbf{N} \\
117\end{array}$} \\
\hline & Honhaar No 33 & Ketchan № 34 & Seidler No 9 & & & \\
\hline Working & $11(33.3 \%)$ & $11(32.4 \%)$ & $1(11.1 \%)$ & $23(30.3 \%)$ & $12(29.3 \%)$ & $35(29.9 \%)$ \\
\hline Unemployed & $22(66.7 \%)$ & $23(67.6 \%)$ & $8(88.9 \%)$ & $53(69.7 \%)$ & $29(70.7 \%)$ & $82(70.1 \%)$ \\
\hline $\mathrm{X} 2, \mathrm{P}$ & \multicolumn{3}{|c|}{$\chi^{2}=1,782 ; p_{1}=0,410$} & \multicolumn{3}{|l|}{$\chi^{2}=0,013 ; p_{2}=0,911$} \\
\hline Disabled & $14(42.4 \%)$ & $23(67.6 \%)$ & $7(77.8 \%)$ & $44(68.4 \%)$ & $26(77.1 \%)$ & $70(59.8 \%)$ \\
\hline I & & $4(11.8 \%)$ & $2(22.2 \%)$ & $6(7.9 \%)$ & $4(9.8 \%)$ & $10(8.5 \%)$ \\
\hline II & $14(42.4 \%)$ & $16(47.1 \%)$ & $4(44.4 \%)$ & $34(44.7 \%)$ & $20(48.8 \%)$ & $54(46.2 \%)$ \\
\hline III & & $3(8.8 \%)$ & $1(11.1 \%)$ & $4(5.3 \%)$ & $2(4.9 \%)$ & $6(5.1 \%)$ \\
\hline
\end{tabular}




\begin{tabular}{|c|c|c|c|c|c|c|}
\hline \multirow{2}{*}{ Social status of patients } & \multicolumn{3}{|c|}{ Indigenous people } & \multirow{2}{*}{$\begin{array}{l}\text { Indigenouspeopl } \\
\text { e. Total: № } 76\end{array}$} & \multirow{2}{*}{$\begin{array}{l}\text { Non-indigenous } \\
\text { people № } 41\end{array}$} & \multirow{2}{*}{$\begin{array}{l}\text { Altogether: № } \\
117\end{array}$} \\
\hline & Honhaar No 33 & Ketchan № 34 & Seidler No 9 & & & \\
\hline $\mathrm{X} 2, \mathrm{P}$ & \multicolumn{3}{|l|}{$\chi^{2}=12,3 ; p_{1}=0,056$} & \multicolumn{3}{|l|}{$\chi^{2}=0,412 ; p_{2}=0,938$} \\
\hline Educated: & $30(90.9 \%)$ & $31(91.2 \%)$ & $8(88.9 \%)$ & $69(78.5 \%)$ & $37(77.1 \%)$ & $106(90.6 \%)$ \\
\hline Full average & $16(48.5 \%)$ & $12(35.3 \%)$ & $2(22.2 \%)$ & $30(39.5 \%)$ & $22(53.7 \%)$ & $52(44.4 \%)$ \\
\hline Incomplete average & $9(7.6 \%)$ & $14(41.2 \%)$ & $5(55.6 \%)$ & $28(36.8 \%)$ & $11(26.8 \%)$ & $39(33.3 \%)$ \\
\hline Average special & $3(9.1 \%)$ & $4(11.8 \%)$ & $1(11.1 \%)$ & $8(10.5 \%)$ & $2(4.9 \%)$ & $10(8.5 \%)$ \\
\hline Higher & $2(6.1 \%)$ & $1(2.9 \%)$ & - & $3(3.9 \%)$ & $2(4.9 \%)$ & $5(4.3 \%)$ \\
\hline Uneducated: & $3(9.1 \%)$ & $3(8.8 \%)$ & $1(11.1 \%)$ & $7(9.2 \%)$ & $4(9.8 \%)$ & $11(9.4 \%)$ \\
\hline $\mathrm{X} 2, \mathrm{P}$ & \multicolumn{3}{|c|}{$\chi 2=4,331 ; p_{1}=0,826$} & \multicolumn{3}{|c|}{$\chi^{2}=3,063 ; \mathrm{p}_{2}=0,547$} \\
\hline Family & $16(48.5 \%)$ & $18(52.9 \%)$ & $6(66.7 \%)$ & $40(52.6 \%)$ & $25(61.0 \%)$ & $65(55.6 \%)$ \\
\hline Single & $17(51.5 \%)$ & $16(47.1 \%)$ & $3(33.3 \%)$ & $36(47.4 \%)$ & $16(39.0 \%)$ & $52(44.4 \%)$ \\
\hline $\mathrm{X} 2, \mathrm{P}$ & \multicolumn{3}{|c|}{$\chi^{2}=0,940 ; \mathrm{p}_{1}=0,625$} & \multicolumn{3}{|l|}{$\chi^{2}=0,751 ; \mathrm{p}_{2}=0,386$} \\
\hline
\end{tabular}

Note: the statistical significance of the differences between the indicators:

$\mathrm{p}_{1}$ - Indigenous by mehelles (by $\chi 2$-Pearson)

$\mathrm{p}_{2}$ - Indigenous and non-indigenous (by $\chi 2$ Pearson)

During the study, some ethnic characteristics of the indigenous and non-indigenous population were studied. According to the literature, out of 318 clinical studies in recent years concerning the ethnic characteristics of populations with respect to epilepsy, $6.6 \%$ of the works showed the racial identity of the study participants, and only $1.9 \%$ attempted to analyze ethnic characteristics $[12,13]$. In the studied population, epilepsy sufferers were highly religious, while believers among the sick from the indigenous population prevailed over non-indigenous ones. In ethnic subpopulations, patients differed in the form of expression of religious beliefs. Patients from Honhaar and Kechan mehelle performed religious rituals in the form of strict adherence to established religious rules, which was supported by relatives and friends in the family and this contributed to the improvement of their mental health and positively influenced QoL. There is an opinion that the treatment of some diseases is possible through the recitation of the verses of the Qur'an [26-28]. At the same time, the religious bias of the sick from the Seidler mehelle, set them up on the wrong path of getting rid of the disease only with the help of prayers. Using prayers to combat their fear of subsequent seizures, they refused medication, which increased the severity of the seizures, complicated the course of the disease and contributed to the deterioration of QoL. It is known that even in ancient times, epilepsy was associated with the introduction into the body of the spirit, the devil, was considered as a result of divine destiny and was healed with spells to no avail [29].

Table 2. Results of testing of epilepsy pacients questionnaire QOLIE-10.

\begin{tabular}{|c|c|c|c|c|c|c|c|c|}
\hline \multirow[b]{2}{*}{ Points } & \multicolumn{4}{|c|}{ Indigenous people (meshelles) No. 76} & \multirow{2}{*}{$\begin{array}{l}\text { Non-indigenous } \\
\text { population No. } 41\end{array}$} & \multirow{2}{*}{$\begin{array}{l}\text { Altogether: } \\
\text { No. } 117\end{array}$} & \multirow[b]{2}{*}{ p1 } & \multirow[b]{2}{*}{ p2 } \\
\hline & $\begin{array}{l}\text { Honhaar No. } \\
33\end{array}$ & $\begin{array}{l}\text { Kechan No. } \\
34\end{array}$ & Seidler No. 9 & Altogether: & & & & \\
\hline A-energy & $4.58 \pm 0.71$ & $4.47 \pm 0.11$ & $4.33 \pm 0.24$ & $4.50 \pm 0.08$ & $4.46 \pm 0.09$ & $4.49 \pm 0.06$ & 0.773 & \\
\hline C-activity (driving) & $3.79 \pm 0.14$ & $3.32 \pm 0.21$ & $3.00 \pm 0.44$ & $3.49 \pm 0.12$ & $3.41 \pm 0.16$ & $3.46 \pm 0.10$ & 0.730 & 0.077 \\
\hline D - memory & $4.03 \pm 0.03$ & $4.06 \pm 0.04$ & $3.67 \pm 0.33$ & $4.00 \pm 0.05$ & $4.10 \pm 0.05$ & $4.03 \pm 0.03$ & 0.174 & 0.025 \\
\hline E-influence AED & $3.85 \pm 0.12$ & $3.62 \pm 0.13$ & $3.33 \pm 0.33$ & $3.68 \pm 0.09$ & $3.90 \pm 0.13$ & $3.76 \pm 0.07$ & 0.157 & \\
\hline G-QoL subjective & $4.06 \pm 0.12$ & $4.12 \pm 0.12$ & $3.89 \pm 0.26$ & $4.07 \pm 0.08$ & $3.95 \pm 0.10$ & $4.03 \pm 0.06$ & 0.401 & \\
\hline QoL-objective & $27.8 \pm 0.05$ & $26.7 \pm 0.05$ & $26.2 \pm 1.5$ & $27.1 \pm 0.3$ & $27.0 \pm 0.4$ & $27.1 \pm 0.3$ & 0.852 & \\
\hline
\end{tabular}

Note: the statistical significance of the differences between the indicators:

$\mathrm{p}_{1}$ - Indigenous and non-indigenous (according to $\chi 2$ Pearson)

$\mathrm{p}_{2}$ - Indigenous by mehelles (by $\chi 2$-Pearson)

It follows from Table 2 that among ethnic subpopulations of patients from Kechan mehelle according to the QOLIE-10 questionnaire "subjective assessment of QoL", "energy", "memory" ( $\mathrm{p}=0.025)$, QoL was assessed low, which was influenced by the severity of seizures (27 points in 19 (55.8\%) cases) and high (subclinical in $19(52.9 \%)$ and clinical in 8 $(32.4 \%)$ cases) levels of anxiety and depression. The high assessment of QoL on the items "depression and loss of mental strength", "fear of repeated seizures" and "the effect of AED on the body" was influenced by their religiosity and a high percentage (18 (52.9\%) of married patients). Signs of auto stigmatization lay at the heart of the low QoL score in patients from Honhaar mechelle on the items "subjective QoL assessment", "energy", "memory" $(\mathrm{p}=0.025)$ and "fear of recurrent seizures" $(p=0.033)$. Clinical manifestations of epilepsy under conditions of a relatively high level of education (21 (63.6\%) cases), the number of workers (11 $(33.3 \%)$ cases), with inherent premorbid volitional character traits in patients from the Honhaar mehelle, prevented them from achieving their goals in life, which increased the level of anxiety and depression (subclinicall in 21 (51.5\%) cases, clinically in $4(12.1 \%)$ cases) and negatively affected their QoL. The majority of patients from Honhaar mehelle working as chauffeurs reacted negatively to the point 
"driving vehicles". The inability to drive a car due to frequent seizures also, interfering with the self-realization of patients, worsened the psych emotional status and negatively affected the assessment of their QoL ( $\mathrm{p}=0.077)$. The QoL study on this item in patients from other groups (Kechan mehelle, Seidler mehelle, non-indigenous residents) did not reveal significant changes due to inability to drive a car. The low assessment of QoL by patients from Seidler mehelle on the items "energy", "memory", "depression and loss of mental strength", "fear of repeated seizures" ( $p=0.033$ ), "subjective assessment of QoL" was influenced by the severity of seizures $(21(44.4 \%))$ and the level of psych emotional status, expressed subclinicall in $6(55 \%)$ individuals, as well as their inherent ethnic characteristics: scarce premorbid personality traits aimed only at preserving marriage and material wellbeing, a form of expression of religious beliefs and upbringing in the parental family. The older generation, which received a strict upbringing without encouragement for intellectual development, passed on these traditions to their children and grandchildren, strengthening in subsequent generations subordination, lack of initiative, which contributed to the formation of a passive personality with disabilities both in terms of education and employment.

In patients from the non-indigenous population, the low QoL score for the item "memory", "the effect of AED on the body", "energy" could be influenced by the severity of seizures (20 points in $20(48.8 \%)$ cases) and equally high subclinical and clinical levels of anxiety and depression (16 (39.0\%) cases each).

The study of the frequency and structure of disability also revealed a high level of incidence among them of disabled persons II (20 (48.8\%) cases) and I group (4 (9.8\%) cases), which indicates a severe course of the disease in patients and explains the high incidence of unemployed among them. (29 (70.7\%) cases).

\section{Conclusion}

Thus, according to the objective indicators of the QOLIE-10 questionnaire, it follows that the quality of life in all patients in the population was low $(27.1 \pm 0.3)$. The reason for the low QoL score was the high severity and frequency of seizures, the pronounced level of impairment of the psych emotional status and social adaptation of patients with epilepsy. Certain ethnocultural characteristics of patients affected the assessment of QoL of patients both positively and negatively: a form of expression of religious beliefs, which, in the form of a clear implementation of the established religious rules, had a positive effect on the quality of life of patients from the Honhaar and Kechan mehelle, and mysticism in relation to religion, a form of upbringing in a family without encouraging intellectual development and even prohibitions on obtaining an education, contributed to the formation passive personality with disabilities among patients from Seidler mehelle, which affected their QoL negatively. The desire to preserve the marriage is positive, while the concealment of the disease negatively affected the quality of life of patients from all ethnic groups in the studied population.

\section{Conflict of Interest Statement}

The authors declare no competing interests.

\section{References}

[1] Gecht, A. B. Milchakova L. E., Churilin Yu. Yu. (2006). Epidemiology of epilepsy in Russia. J. neurol. and a psychiatrist. them. C. S. Korsakov, V. 106, No. 1, P. 3.

[2] Grebenyuk O. V., Kazennykh T. V., Alifirova V. M., Svetlik M. V., Bokhan N. A. (2017). Gender aspects of medical and social adaptation in adults with early onset of epilepsy. Journal of Neurology and Psychiatry. S. S. Korsakov. T. 117. No. 6. P. 53-58.

[3] Karlov V. A., Gnezditsky V. V., Geybatova L. G. (2012). Epilepsy and paroxysmal states. T. 4, No. 4. - S. 32-39.

[4] Kisten O. V., Evstigneev V. V., Ulashchik V. S., Dubovik B. V. (2009). Transcranial magnetic stimulation in the diagnosis and treatment of epilepsy. News of biomedical sciences. 4: 99-108.

[5] Magalov Sh. I. Epilepsy. (2014) Oguz Eli. p. 159.

[6] Shorvon S. et al. (1995). The epidemiological of epilepsy. Lecture notes. British Branch of the Internacional League against epilepsy. Oxford: Keble College. P. 1-6.

[7] Magalov Sh. I. et al. Drug treatment of epilepsy in Ganja: effectiveness and inadequacy. (2014). Azerbaijan Psychiatric Journal. No. 1 (26) - p. 84-94.

[8] Magalov Sh. I. and others. The state of the epileptological service in Azerbaijan and the ways of its improvement. (2017). From the materials of the scientific-practical conference dedicated to the 120th anniversary of the birth of SG Akhundov. p.-312.

[9] Mikhailov V. A., Druzhinin A. K., Lipatova L. V., Kissin M. Ya., Bocharov V. V. (2015). Non-psychotic mental disorders in elderly patients with epilepsy and their impact on the quality of life. V. M. Bekhterev. No. 2. P. 59-67.

[10] Social aspects of epilepsy. Created by Epilepsy. su. Copyright (C) 2019.

[11] Titov V. I. (1998). The activities of the medical service of medical and labor workshops in modern conditions // Rehabilitation in psychiatry (clinical and social aspects). Tomsk: Publishing house of scientific and technical literature. 190-191.

[12] Burneo J. G., Martin R. (2004). Reporting race/ethnicity in epilepsy clinical trials [Text] Epilepsy Behaviour. №5. -P. 743-745.

[13] Hansen B., Szaflarski M., Bebin E. M., Szaflarski J. P. (2018). Affiliate stigma and caregiver burden in intractable epilepsy. Epilepsy Behaviour. Vol. 7. № 85. P. 1-6. DOI: 10.1016/j.yebeh.2018.05.028.

[14] Syvertsen M., Nakken K. O., Edland A., Hansen G., Hellum M. K., Koht J. (2015). Prevalence and etiology of epilepsy in a Norwegian county - population based study. Epilepsia. Vol. 56. № 5. P. 699-706. 
[15] Tedrus G. M., Fonseca L. C., Carvalho R. M. (2013). Epilepsy and quality of life: socio-demographic and clinical aspects, and psychiatric co-morbidity. Arq. Neuropsiquiatr. Vol. 71. № 6. P. 385-391.

[16] Guidelines for epidemiologic studies on epilepsy. (1993). Commission on epidemiology and prognosis. International League against epilepsy. Epilepsia. 34 (4): 592-596. DOI: 10.1111/j.1528-1157.1993. tb00433.x.

[17] Novruz G. K. (2017). "Ancient Mashtaga". Kovsar, p. 580.

[18] Sarabsky G. (1958). "Old Baku" p. 238-239.

[19] Mukhin K. Yu., Petrukhin A. S. Idiopathic generalized epilepsy: taxonomy, diagnosis, therapy. - // M.: Art-Business Center, 2000-p. 285-318.

[20] Radhakrishnan K, Pandian J. D., Santosh Kumar T., Thomas S. V., Deetha T. D., Sarma P. S., Jayachandran D., Mohammed E. (2000). Prevalence, knowledge, attitude and practice of Epilepsy in Kerala, South India. Epilepsia. 41: 1027-1035. https://doi.org/10.1016/j.yebeh.2006.07.009.

[21] Winkler A. S., Kerschbaumsteiner K., Stelzhammer B. et al. (2009). Prevalence, incidence, and clinical characteristics of epilepsy - a community - based door-to-door study in northern Tanzania. J. Epilepsia. Vol. 50. - P. 2310-2313.

[22] Mukuku O., Nawej P., Bugeme M., Nduu F., Makan Mawaw
P., Oscar Numbi Luboya. (2020). Epidemiology of Epilepsy in Lubumbashi, Democratic Republic of Congo. Neurology Research International. ID 5621461 | 5 pages | https://doi.org/10.1155/2020/5621461.

[23] Donoghue M. F., Duncan J. S., Sander J. V. (1996). National Hospital Seizure Scale. (NHS3). Epilepsy. 37. No. 6, 1996. Pp. 563-571.

[24] Minac M. E., Feng M. C. (2016). Assessment of Activities of Daily Living, Self-Care, and Independence. Arch. Clin. Neuropsychol. Vol. 31. No. 6. P. 506-516.

[25] Jiang H., Wang L., Zhang Q., Liu D. X., Ding J., Lei Z., Lu Q., Pan F. (2015). Family functioning, marital satisfaction and social support in hemodialysis patients and their spouses. Stress Health. 31: 166-174. https://doi.org/10.1002/smi.2541.

[26] Mustafa Cetin. (1992). Category of Healing in the Qur'an (in Turkish). Journal of the Faculty of Theology of the University p. 70 .

[27] Suat Yildirim. (1990). Holy Quran and discoveries in the field of natural sciences (in Turkish). Ankara. p. 7.

[28] Tantawi, al-Jawahir fi tafsiri'l-Kur'an (in Arabic). Cairo, 1350/1931, III, 1.

[29] Kissin M. Ya. (2009). Clinical epileptology. Neurology and psychiatry. ISBN: 978-5-9704-0863-6. 